\title{
Post Abortal Inversion of Uterus. A Unique Case
}

\section{Abstract}

Inversion of uterus following abortion is rare but fatal complications. If reposition is not done it leads to life threatening hemorrhage and shock. Only 2 cases in literature have occurred so far.. Here we are reporting a rare case of inversion uterus following abortion.

Keywords: Hemorrhage, Abortion, Vaginal deliveries, Inversion
Volume 6 Issue 6 - 2017

\author{
Khushpreet Kaur, Rama Garg, Arwinder Kaur, \\ Sangita Aggarwal, Ruchi Jindal \\ Department of Obstetrics and Gynaecology, Govt. Medical \\ College Patiala, India
}

Correspondence: Ruchi Jindal, Department of obstetrics and Gynaecology, Govt. Medical College Patiala, Punjab I4700 I, India, Tel 8195896300,Email docruchib@yahoo.com

Received: February 26, 2017 | Published: May 04, 2017

\section{Introduction}

Acute puerperal uterine inversion is rare but potentially fatal obstetric emergency. When repositioning of the uterus is not immediate, excessive bleeding can cause haemodynamic instability and shock. ${ }^{1}$ Uterine inversion following abortion is extremely rare and only two cases have been reported in the literature till now. We are reporting a rare case of inversion uterus following abortion.

\section{Case report}

28 years female P3L3A1 admitted in the department of Obst. \& Gynae on 1/2/2017 at GMC Patiala, referred from a district hospital with foul smelling mass protruding out of vagina and severe anaemia. She took self-medication in the form of MTP pill on 5/1/2017 at three and half month POG. . She expelled a small fetus followed by off and on excessive bleeding thereafter for 1 month.

a. She had all full term normal vaginal deliveries, hospital conducted with last child birth one and half year back following which she had regular menstrual periods. On arrival to gynae emergency of Govt. Medical College, Patiala, Her general condition was poor. Pallor+++, vitals were PR-100/min BP-116/6, RR-29/min, Spo298\%, U.O.-800 ml clear.

b. P/A-Soft, Non Tender, no mass palpable.

c. P/V examination revealed a broad, globular, reddish, purple necrotic mass of $7 \times 7 \mathrm{~cm}$ coming out of vulva with very offensive smell. Placenta like tissue got separated during examination. A mass of $5 \times 5 \mathrm{~cm}$ was lying in the vagina with cervical rim felt higher up around it. There was no active bleeding from surface.

d. P/R fundus of the uterus could not be felt a cup like depression was felt. The provisional diagnosis of inversion uterus following abortion was made and findings were confirmed on EUA. It was complete inversion of uterus (Figure $1 \& 2$ ).

e. Under cover of antibiotics and blood transfusion, hydrostatic reduction using warm saline was done. Complete correction of inversion achieved and uterotonics given. Vaginal packing done. Total of 5 BTs and 3 FFPs were given. Post op. period was uneventful with no febrile morbidity. On $\mathrm{p} / \mathrm{v}$ exam cervix downwards, extospatulus, ut A/V 8 week's size. The uterus was sonographically clear of placental fragments.

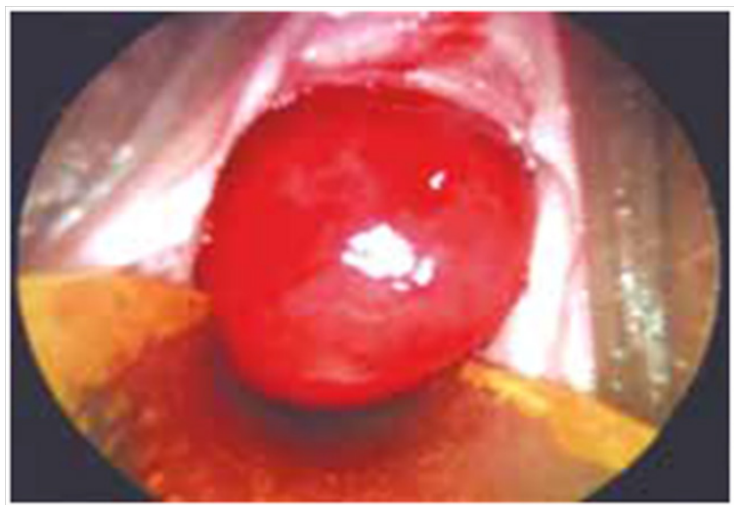

Figure I P/V examination of vulva.

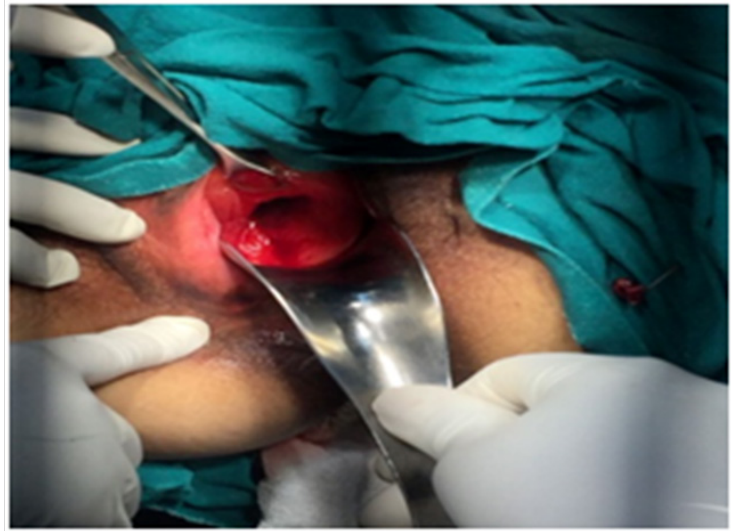

Figure 2 After Correction of Inversion.

\section{Discussion}

a. Puerperal and non-puerperal uterine inversion is seen rarely, but following abortion so rare that majority of medical professional in the course of their professional career never see a case.

b. Acute puerperal uterine inversion is a rare but potentially fatal obstetric emergency. A prompt recognition enables immediate repositioning of the uterus before it becomes edematous and incarcerated by a constriction ring which requires surgical intervention later on. ${ }^{2}$ 
c. Haemorrhage, perforation of uterus, sepsis, septic shock, pelvic abcess, perforation of bowel and bladder are the complications of abortion. But inversion of uterus is not a reported post abortal complication. This is described as a rare complication of puerperium. ${ }^{3}$ It is a potentially life threatening condition and is associated with high maternal morbidity and mortality in absence of early recognition and treatment in acute state. Hydrostatic reduction first described by O' Sullivan in the British medical journal in 1945, a bag of warmed fluid is hung on a pole used for intravenous fluids above the level of the patient and allowed to flow via tubing into the vagina. The pressure of the water held in the place by the clinician hands results in the correction of inversion.

d. Momani \& Hassan ${ }^{4}$ reported successful correction in five cases of inversion within a 7 years period using this method. More recently, Ogueh \& Ayida $^{5}$ described a new technique of hydrostatic pressure. ${ }^{5}$ Citing difficulty in maintaining an adequate water seal to generate the pressure required, the authors suggest attaching the intravenous tubing to a silicon cup used in vacuum extraction. By placing the cup within the vagina an excellent seal is created and adequate hydrostatic pressure for inversion correction is thus produced. Although success with this technique is cited in literature, there has been no discussion of the risk of air or amniotic fluid embolism.

The ease with which this minimally invasive maneuver can be carried out and low incidence of failure, make the O' Sullivans hydrostatic procedure very suitable for reduction of the acutely inverted uterus in the postpartum period. In this case patient never gave $\mathrm{h} / \mathrm{o}$ manipulation after expulsion. Inversion of uterus following abortion may be because of traction on placenta. Repositioning of the uterus by hydrostatic reduction is one of the most popular methods and rewarded with normal menstruation. ${ }^{6}$ and even normal reproduction. Uterine sparing surgery should be the principal mode of treatment in young women.

\section{Conclusion}

a. Inversion of the uterus should be kept in mind as a complication of abortion.

b. In every case of inversion uterus esp. In young women O' Sullivan hydrostatic reduction should be tried before surgical procedures.

\section{Acknowledgments}

None.

\section{Conflicts of interest}

None.

\section{References}

1. Naznee Begam, Sheekha Gangoli. Inversion of Uterus - Presenting as a Complication of Abortion. Bangladesh of $J$ Obstet Gynaecol. 2014;29(1):54-55.

2. Sunita, Vani Ram Kumar. An unsual case of uterine inversion. Journal of Clinical and Diagnostic Research. 2011;5(3):650-651.

3. Marjolijn de Vries, Denise AM Perquin. Nonpuernal Uterine inversion due to submucous myoma in a young woman: a case report. $J$ Med Case Rep. 2010;4:21.

4. Momani AW, Hassan A. Treatment of puerperal uterine inversion by the hydrostatic method: reports of five cases. Eur J Obstet Gynecol Reprod Biol. 1989;32(3):281-285.

5. Ogueh O, Ayida G. Acute uterine inversion: a new technique of hydrostatic replacement. Br J Obstet Gynaecol. 1997;104(8):951-952.

6. SE Adaji, SB Bature, S Nasir, et al. Uterine inversion complicating traditional termination of pregnancy. Obstetrics and Gynaecology Forum. 2005;15(4):25-26. 